Acta Zoológica Mexicana (nueva serie), Volume 37, 1-8.

Original paper

\title{
Comparison of the efficiency and ethical implications of pitfall and Tomahawk traps on Virginia opposums (Didelphis virginiana)
}

\section{Comparación de la eficiencia e implicaciones éticas de las trampas de caída y Tomahawk en tlacuache norteño (Didelphis virginiana)}

\section{1,2*YURY GLEBSKIY, (D) 'ZENÓN CANO-SANTANA}

\footnotetext{
${ }^{1}$ Laboratorio de Interacciones y Procesos Ecológicos, Facultad de Ciencias, Universidad Nacional Autónoma de México. Circuito exterior S/N, C.U., Coyoacán, 04510 CDMX.

${ }^{2}$ Posgrado en Ciencias Biológicas, Universidad Nacional Autónoma de México.
}

Responsible editor: Sonia Gallina

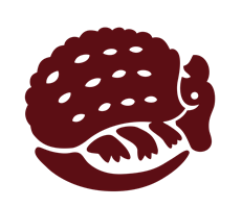

OPEN ACCESS

*Corresponding author:

(iD) Yury Glebskiy agloti@ciencias.unam.mx

Cite:

Glebskiy, Y., Cano-Santana, Z. (2021) Comparison of the efficiency and ethical implications of pitfall and Tomahawk traps on Virginia opposums (Didelphis virginiana). Acta Zoológica Mexicana (nueva serie), 37, 1-8.

10.21829/azm.2021.3712375 elocation-id: e3712375

Received: 10 November 2020 Accepted: 22 September 2021

Published: 18 October 2021
ABSTRACT. The choice of methods for trapping animals can greatly affect the studies and their results, despite that there are relatively few studies on the matter. Thus, the purpose of this study is to compare two common methods of live trapping (Tomahawk traps and pitfall traps), their efficiency and ethical implications for trapping Virginia opossums (Didelphis virginiana). Traps were located in a paired design, the trapped animals were checked for sex, injuries caused by the trap and stress level, then marked and released in the same spot. At the same time, costs of both trap types were compared. Tomahawk traps were $60 \%$ more efficient to trap opossums but the pitfall traps had better results in all the other categories: were more cost-effective, did not injure the animals as often and were less stressful. Neither type of trap presented bias in sex proportion or number of recaptured animals. In general, both types of traps resulted to be effective, the pitfall trap was the better option in almost all of the categories but has the disadvantage that in the infrequent event of two males being caught on in the same trap, they are likely to fight.

Key words: cost-efficiency; Didelphis virginiana; Mexico; REPSA; 
trapping methods

RESUMEN. La elección del método de trampeo de los animales puede afectar de manera considerable los resultados de los estudios, a pesar de esto hay pocos estudios de este tema. Por lo tanto, el objetivo de este trabajo es comparar dos métodos comunes para capturar animales vivos (trampas Tomahawk y trampas de caída), y su eficiencia e implicaciones éticas para atrapar tlacuaches norteños (Didelphis virginiana). Las trampas se colocaron en un diseño pareado; a los animales se les tomaron los datos de sexo, heridas causadas por la trampa y nivel de estrés, posteriormente se marcaron y se liberaron en el sitio de captura. También se compararon los costos de ambos tipos de trampa. Las trampas Tomahawk resultaron $60 \%$ más eficientes, pero las trampas de caída tuvieron mejores resultados en todos los demás aspectos: tuvieron mejor costoeficiencia, rara vez causaban heridas a los animales y estos estaban menos estresados. Ningún tipo de trampa presentó sesgos en la proporción sexual ni el número de animales recapturados. De manera general, ambos tipos de trampa resultaron eficientes, la trampa de caída fue la mejor en la mayoría de los aspectos, pero su desventaja consiste en que en el poco frecuente caso de que dos machos sean capturados en la misma trampa, es muy posible que se peleen.

Palabras clave: costo-eficiencia; Didelphis virginiana; México; REPSA; métodos de trampeo

\section{INTRODUCTION}

Trapping animals could be the single most important challenge in mammal ecology research. The technics and equipment (e.g., traps) or tools for this can be costly, time-consuming (Trapp \& Flaherty, 2017; Waubdy et al., 2019), and can have a negative impact on the welfare of the individuals, which is detrimental both from an ethical point of view (Waubdy et al., 2019) and for the research results (for example in capture-recapture estimates; Waubdy et al., 2019).

The two most popular live trapping techniques are pitfall traps and box traps (most commonly Sherman and Tomahawk; Santos-Filho et al., 2015; Trapp \& Flaherty, 2017; Waubdy et al., 2019). These techniques have been previously compared for small mammals in terms of number of animals captured, richness, and diversity obtained by each method, showing mixed results (Hice \& Velazco, 2013; Santos-Filho et al., 2015; Waubdy et al., 2019); thus, no single method can be declared as the optimal, yet several studies show that the combined use of methods is the best option for diversity studies (Palmeirim et al., 2019). Despite this, studies targeting a single species are rare, and few include the ethical implications (but see Pestell \& Petit, 2007) and the damage caused to the animal during capture, thus creating a knowledge gap (especially for medium-sized mammals). At the same time, most recent studies were performed in tropical forests (Santos-Filho et al., 2015; Helder et al., 2019), leaving other ecosystems like xerophylous shrublands relatively unexplored.

The objective of this study is to compare the efficiency of the Tomahawk and pitfall traps for trapping opossums (Didelphis virginiana; Kerr, 1792) as well as the differences in the sex ratios and physical and psychological effects of both techniques. 


\section{MATERIALS AND METHODS}

The study was conducted in "Reserva Ecológica del Pedregal de San Ángel" (REPSA) an ecological reserve located in Mexico City (Mexico). The dominant vegetation type is xerophylous shrubs with an important cover of herbaceous vegetation, trees are relatively common but generally small, and there is an important variation in vegetation and local conditions (Cano-Santana, 1994; Rzedowski, 1954). The reserve terrain is rugged and soil scarce, as it is located on a recent lava field, with a mean rainfall of $833 \mathrm{~mm}$ and average temperature of $15.5^{\circ} \mathrm{C}$ (detailed description in Rzedowski, 1954; REPSA, 2020).

The trapping was designed for Virginia opossum (hereafter opossum) Didelphis virginiana, a medium-sized omnivore (description given in McManus, 1974) that is common in the study site (Arenas-Pérez, 2016).

Traps were set-up in a paired design with a Tomahawk $(27 \times 27 \times 72 \mathrm{~cm})$ and a pitfall trap located at no more than $5 \mathrm{~m}$ from each other; the trapping points were situated between 30 and $500 \mathrm{~m}$ apart. Since the soil is scarce in the study site, plastic buckets $(75 \mathrm{~cm}$ high and $44 \mathrm{~cm}$ wide) were used as pitfall traps (similar to Helder et al., 2019) and installed close to big rocks or trees that allowed the opossums to easily climb inside (see Fig. 1), the traps were secured by ropes to avoid falling, covered with leaves or grass and filled with a small amount of the same material, this was made to: 1) hide the trap, 2) soften the impact from the fall and 3) provide material for a temporary nest for the animal (since external materials may interfere with the Tomahawk activation mechanism no vegetation was added to this type of trap). It is to be noted that the pitfall traps here are not used in the most traditional way, by digging holes in the ground (like Palmeirim et al., 2019). Still, the method used here is the only possible alternative of using pitfall traps in locations with scarce soil, and it has the advantage of being less labor-intensive. Furthermore, there is no disturbance in the soil, and damage to the root system; this is especially important when digging traps for medium and large animals since the volume of the soil removed could be considerable.

Trapping was conducted from November 20 to December 10 of 2019, during the dry season in the REPSA. Traps were activated between 19:00 and 22:00 and inspected between 7:00 and 10:00 local time.

Four to six pairs of traps were active each night, and each 7-8 nights the location of the traps was changed, giving 108 trap-nights for each trap type. Commercial cat food (80 g of Whiskas ${ }^{\circledR}$ paté, beef, or tuna flavor) and apples (one apple per trap) were used as bait. The data collected: stress level (considering that a sleeping opossum has a low-stress level and if awaken it is stressed), sex, and injuries caused by the trap. In addition, the animals were marked with Methylene blue on left or right foot according to the trap type they were found in. To ensure that the manipulation of the animals did not affect the stress levels, this factor was the first measured, carefully approaching the trap to look if the animals were active and its position (this allows to distinguish between sleeping and catatonia, a defense mechanism used by opossums). 
Sleeping was considered as a low-stress sign because opossums are nocturnal animals, and previous studies show that their activity in the morning (when the traps were inspected) is very low (Coronel-Arellano et al., 2021), and the normal behavior at this time is sleeping (McManus, 1971). Therefore, an awake animal found in the trap indicates that normal activities and sleeping patterns were affected (almost certainly by the stress caused by trapping).

A sign test was used to compare the effectiveness of the traps, and a $\chi 2$ test was used to compare the other characteristics (sex proportions, proportions of recaptures, number of injured and sleeping individuals; see Table 1). Since Tomahawk traps were more effective than pitfall when comparing the sex proportions and the number of injured and sleeping animals, the null hypothesis was a $0.625: 0.375$ ratio, since this is the ratio of captures by the two types of traps. Analyses were made using the R statistical package BADA (Arnholt \& Evans, 2017; R Core Team, 2018).

The lowest current prices for Tomahawk traps in Mexico were obtained, considering that traps fitted for this species were at least $25 \mathrm{~cm}$ wide and $25 \mathrm{~cm}$ high.

Table 1. Comparison of the number of Didelphis virginiana trapped with Tomahawk and pitfall traps. $p$ value of the analysis used to compare the treatments: sign test for the total captures and for the remaining data a $\chi 2$ with a null hypothesis of a ratio of 0.625:0.375 (equal to the ratio of the total captures by trap type).

\begin{tabular}{llll}
\hline Variable & Tomahawk & Pitfall & $\boldsymbol{p}$ \\
\hline Total captured & 100 & 61 & $<0.001$ \\
Female (including recaptures) & 54 & 35 & 0.722 \\
Male (including recaptures) & 46 & 25 & 0.690 \\
Females (no recaptures) & 22 & 16 & 0.558 \\
Males (no recaptures) & 14 & 7 & 0.693 \\
First capture & 36 & 23 & 0.814 \\
Recaptures & 64 & 37 & 0.857 \\
Injured & 27 & 2 & $<0.001$ \\
Sleeping & 14 & 44 & $<0.001$ \\
\hline
\end{tabular}

\section{RESULTS}

A total of 161 captures were made, 100 using Tomahawk traps and 61 using pitfall traps, one animal captured in the pitfall trap managed to escape during the inspection, and no data could be taken; therefore, it was considered for the overall effectiveness analysis but excluded from the rest. The effectiveness of the Tomahawk traps was significantly greater than the pitfall (a $93 \%$ and 56 $\%$ of effectiveness, respectively). The sex ratio did not differ from a 1:1 in Tomahawk and pitfall, nor in the pooled data of both traps (in all cases $p>0.1$ ). At the same time, pitfall traps were less stressful (most of the animals found inside were sleeping) and safer for the opossums, although the percentage of recaptures was the same for both trap types (see Table 1). The lowest cost for a Tomahawk trap was 1,345.00 Mexican Pesos (including shipping), while the cost for the pitfall trap was 100.00 Mexican Pesos (save $92.6 \%$ ) and are readily available. 
Two events of double captures took place in pitfall traps ( $6.6 \%$ of the captures); all animals in double captures were male. In one event (two young males), no signs of interaction between the animals were noticed; in the other (two adult males), the opossums fought, and both exhibited several injuries, although not life threatening (being this two the only ones that suffered injuries in this type of trap). In Tomahawk traps, $27 \%$ of animals suffered some injuries, $22 \%$ in nose and face, $3 \%$ in tail, and $2 \%$ in nose and tail; injuries registered were minor.

Qualitative observation showed that opossums found in the pitfall traps conditioned the trap as a provisional nest using the vegetation provided (Fig. 1) or hide beneath it (this is why one opossum managed to escape). Furthermore, opossums were easier to manipulate when sleeping in both types of traps (especially pitfall traps).
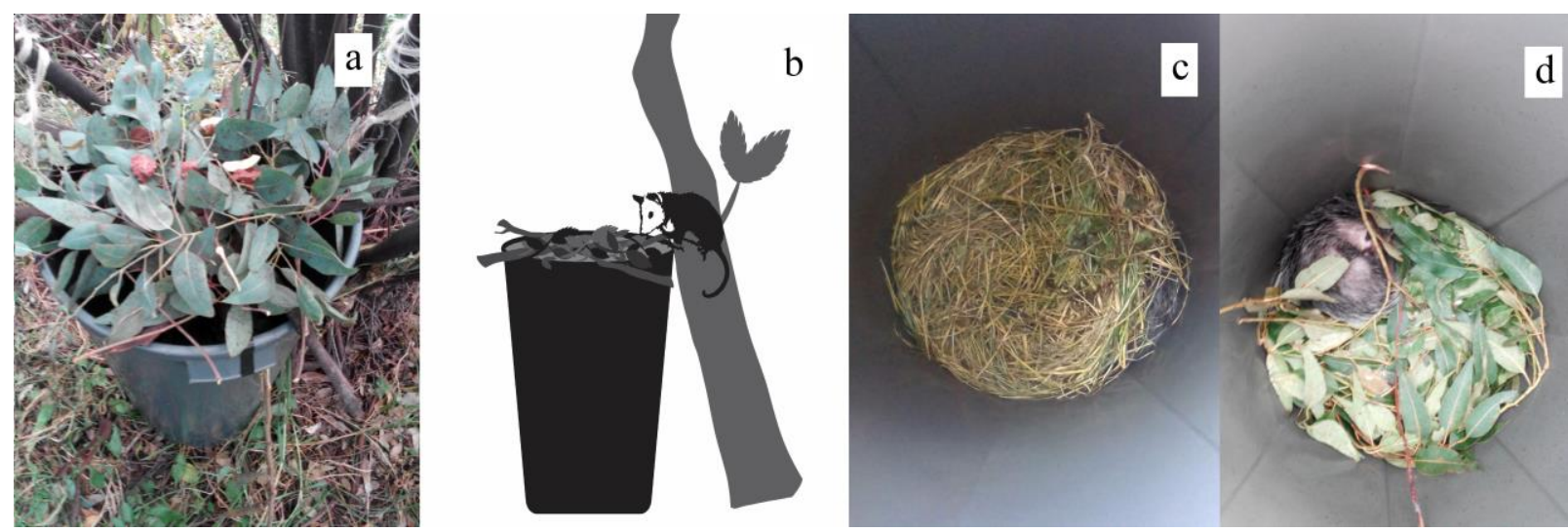

Figure 1. Pitfall trap: a) active trap, notice the rope (upper corners) holding it to the tree; b) schematic of an opossum climbing into the trap (a tree or some substrate is necessary to allow the animal to climb into the opening); c) opossum hiding under the vegetation (in this case is slightly visible in the lower right corner); d) opossum sleeping in the trap.

\section{DISCUSSION}

The first result that stands out is the extremely high efficiency of the traps. In a previous study, Arenas-Pérez (2016), working with the same species in the REPSA reserve in 2014 and 2015, was able to catch 45 individuals in 1,680 trap nights using Tomahawk traps giving an efficiency of 2.7 $\%$ (data provided only for new captures). While in this study, the efficiency of newly captured animals for Tomahawk traps was 13.3 times higher: 36 \% (see Table 1). Considering that ArenasPérez (2016) used several types of bait, including cat food (the main bait in the present study), two explanations for these differences could be made: 1) the previous study was made during the rainy season, and this could affect the food availability and the detectability of the bait, 2) the population increased in size drastically from 2015 to 2019. However, the first explanation is unlikely since the Arenas-Pérez (2016) study was made between May and October and this study in November and December the differences in vegetation between those periods, although noticeable (see CanoSantana, 1994), are not significant enough to cause a tenfold change in captures, and other studies (Pestell \& Petit, 2007) show that differences between trapping periods are smaller than the observed in this work. The second explanation could be related to the program for removing dogs 
(Canis familiaris) from the reserve That took place between 2015 and 2019 and archived the goal of removing most dogs (pers. com. Gil-Alarcón and Arenas-Pérez). With the removal of this predator, opossums became one of the biggest mammals in REPSA (Hortelano-Moncada et al., 2009); the risk of predation is greatly diminished and that could have caused a significant increase in the population and a change in their behavior. Although the population change could be a part of a natural variation or a combination of several of the factors described, thus a long-term monitoring program is recommended.

Tomahawk traps were 1.6 times more effective than pitfall traps. This is consistent with previous studies (Hice \& Velazco, 2013; Santos-Fihlo et al., 2015) that show that Tomahawk traps are more effective to capture species of Didelphis. At the same time, pitfall traps were 13.5 times cheaper, thus being 8.4 times more cost-effective, similar to Waubdy et al. (2019). The greater effectiveness of the Tomahawk traps could be explained in this case by the fact that these traps were located at ground level and did not require to climb, thus the bait inside these traps was found first in the trapping point. This suggests that in absence of Tomahawk traps, pitfall trap efficiency could be greater since the first animal to arrive at the trapping point was more likely to get in the Tomahawk trap, and the captures in the pitfalls were due to posterior arrivals (that in some cases could have not happen). At the same time, $D$. virginiana opossums are good climbers (McManus, 1974), therefore climbing into the pitfall trap wouldn't represent a great effort and other factors could explain the lower efficiency of the traps.

There was no preference of the nether type of trap for the sex of captured individuals. The proportion of male to female individuals did not differ significantly from 1:1 proportion, which is normal for the species (McManus, 1974), suggesting that both methods have little or no bias for the sex and information obtained in studies using these methods is valid.

The number of first captures and recaptures did not differ from the proportions expected among the traps (Table 1). This suggests that the effect of the capture did not affect or affect equally the probability of being captured in the future, thus implying a low psychological impact on the animal, an inefficient learning process, or that the gain of food in the traps outweighs the negative consequences of being trapped. At the same time, opossums suffered more stress and were more commonly injured inside the Tomahawk traps (see Table 1), this is because the Tomahawk traps have wire walls and while the animals were trying to escape through the bars injured the nose, something that cannot happen in a rounded and smooth plastic pitfall trap. Furthermore, the see-through walls of the Tomahawk trap created an illusion of an escape possibility and allowed the opossum to see around, contributing to stress the animal. This was not true for the pitfall traps and could explain why most animals (72\%) captured in pitfall traps were sleeping and thus were less stressed, while only $14 \%$ of the Tomahawk trapped opossums were sleeping. This is especially important since sleeping animals were easier to manipulate as they did not offer much resistance in the first and most difficult moments of handling, which reduces the manipulation time and risk of injuries of both researcher and animal; therefore, the best thing for an animal to do when trapped is to sleep. Another factor that could have contributed to the differences in the stress was the vegetation provided in the pitfall traps that was used to condition the trap as a provisional nest (this cannot be performed in the Tomahawk traps since external 
objects interfere with the activation mechanism). These defects in the Tomahawk traps could be corrected if the walls are lined with a solid material (preferably plastic). The significant disadvantage of the pitfall traps is that they allow for the capture of more than one animal (Waubdy et al., 2019) and the males of this species tend to have antagonistic encounters (McManus, 1974). In this study, there were two double captures, representing $6.6 \%$ of the captured possums; in one (two young males), no signs of fighting were found, but the other pair (two adult males) fought, resulting in injuries for both, the injuries were not life-threatening but more serious than the injures commonly found on the Tomahawk trapped possums. Though it has to be considered that fights are common between possum males (McManus, 1974), and it is unclear if the traps contribute to the frequency or severity of those fights. No female-female or female-male double captures were observed, yet since double captures are rare, it cannot be assured that these are rarer than the male-male encounters.

This suggests that Tomahawk traps are more efficient, but pitfall traps are notoriously cheaper. For ethical implications, it is not clear which is better; the more stressful Tomahawk traps that have a high chance of causing minor injuries or the less stressful pitfall traps that have a low probability of causing wounds, in the infrequent cases that two males are captured together, therefore the decision of which trap to use has to be made case by case. Yet these results suggest that the pitfall traps could be ethically better for species that do not fight when confined to reduced space and for the locations where densities of antagonistic animals are low, and the probability of a double capture is low.

ACKNOWLedgments. We are thankful to the Secretaria Ejecutiva de la Reserva Ecologica del Pedregal de San Ángel team for the authorization to work in the reserve, and support given for this project (including providing the Tomahawk traps for this study), especially to P. A. Arenas Pérez and G. Gil Alarcón. We are also grateful to I. Castellanos Vargas for general support and D. A. Parra Campos for the illustration. This work was possible thanks to a scholarship by the CONACYT to YG (CVU 817316) and a PAPIIT grant IN212121 (El efecto de la urbanización sobre el tlacuache Didelphis virginiana en un matorral xerófilo de la Ciudad de México) to ZCS. The handling was performed under the SEMARNAT permit No. SGPA/DGVS/13527/19.

\section{LITERATURE CITED}

Arenas-Pérez, P. A. (2016) Seroprevalencia de rabia y leptospira en poblaciones de perros de libre rango (Canis familiaris) y tlacuaches (Didelphis spp.) que habitan dos reservas ecológicas. M. Sc. dissertation. Facultad de Medicina Veterinaria y Zootecnia. Universidad Nacional Autónoma de México, Mexico City.

Arnholt, A. T., Evans, B. (2017) BSDA: Basic Statistics and Data Analysis. R package version 1.2.0. https://CRAN.R-project.org/package=BSDA

Cano-Santana, Z. (1994) Flujo de energía a través de Sphenarium purpurascens (Orthoptera: Acrididae) y productividad primaria neta en una comunidad xerófila. PhD. Dissertation. Unidad Académica de los Ciclos Profesional y de Posgrado, Colegio de Ciencias y 
Humanidades y Centro de Ecología, Universidad Nacional Autónoma de México, Mexico City.

Coronel-Arellano, H., Rocha-Ortega, M., Gual-Sill, F., Martínez-Meyer, E., Ramos-Rendón, A. K., González-Negrete, M., Gil-Alarcon, G., Zambrano, L. (2021) Raining feral cats and dogs? Implications for the conservation of medium-sized wild mammals in an urban protected area. Urban Ecosystems, 24 (1), 83-94.

Helder, J., Macedo, I., Cruz Loss, M. (2019) A new and simple method to capture small arboreal mammals: the suspended pitfall. Revista Brasileira de Zoociências, 20 (1), 1-14.

Hice, C. L., Velazco, P. M. (2013) Relative effectiveness of several bait and trap types for assessing terrestrial small mammal communities in Neotropical rainforest. Museum of Texas Tech University, $316 \mathrm{pp}$.

Hortelano Moncada, Y., Cervantes, F. A., Trejo, A. (2009) Mamíferos silvestres. Pp. 277-293. In: Lot, A., Cano-Santana, Z. (Eds.). Biodiversidad del ecosistema del Pedregal de San Ángel. Universidad Nacional Autónoma de México, México.

McManus, J. J. (1971) Activity of captive Didelphis marsupialis. Journal of Mammalogy, 52 (4), 846848.

McManus, J. J. (1974) Didelphis virginiana. Mammalian species, 40, 1-6.

Palmeirim, A. F., Benchimol, M., Peres, C. A., Vieira, M. V. (2019) Moving forward on the sampling efficiency of neotropical small mammals: insights from pitfall and camera trapping over traditional live trapping. Mammal Research, 64, 445-454.

Pestell, A. J., Petit, S. (2007) Methods and ethical considerations of pitfall trapping for the western pygmy possum (Cercartetus concinnus Gould) (Marsupialia: Burramyidae), with observations on capture patterns and nest sites. Wildlife Research, 34, 296-305.

R Core Team (2018) R: A language and environment for statistical computing. R Foundation for Statistical Computing, Vienna, Austria. Recovered from: https://www.R-project.org/.

REPSA, Reserva Ecológica del Pedregal de San Ángel (2020) Recovered on March 4th., 2020 from: http://www.repsa.unam.mx/index.php/ubicacion/mapa-del-sitio/44-2013-08-07-13$15-59 / 29$

Rzedowski, J. (1954) Vegetación del Pedregal de San Ángel. Anales de la Escuela Nacional de Ciencias Biológicas IPN México, 8, 59-129.

Santos-Filho, M. D., Lázari, P. R. D., Sousa, C. P. F. D., Canale, G. R. (2015) Trap efficiency evaluation for small mammals in the southern Amazon. Acta Amazonica, 45, 187-194.

Trapp, S. E., Flaherty, E. A. (2017) Noninvasive and cost-effective trapping method for monitoring sensitive mammal populations. Wildlife Society Bulletin, 41, 770-775.

Waudby, H. P., Petit, S., Gill, M. J. (2019) The scientific, financial and ethical implications of three common wildlife-trapping designs. Wildlife Research, 46, 690-700. 